\title{
RANCANGAN APLIKASI PENGAMANAN DATA DENGAN ALGORITMA ADVANCED ENCYPTION STANDARD (AES)
}

\author{
Angga Aditya Permana ${ }^{1}$, Desi Nurnaningsih ${ }^{2}$ \\ ${ }^{1,2}$ Universitas Muhammadiyah Tangerang / Fakultas Teknik, Program Studi Informatika \\ Jl. Perintis Kemerdekaan 1/33 Cikokol Kota Tangerang TLP. 02155793251 \\ e-mail: angga.permana@umt.ac.id ${ }^{1}$, desi.nurnaningsih@umt.ac.id ${ }^{2}$
}

\begin{abstract}
ABSTRAK
Data sangatlah berharga bagi semua pengguna komputer, belakangan ini kriptografi menjadi metode yang digunakan dalam mengamankan data. Kriptografi adalah ilmu yang mempelajari teknik-teknik matematika dalam mengamankan suatu informasi atau pesan asli (Plainteks) menjadi sebuah teks tersembunyi (Chiperteks) dan kemudian di ubah menjadi pesan asli kembali. Kriptografi mempunyai tiga unsur penting yaitu pembangkitan kunci, enkripsi dan deskipsi. Dalam kriptografi di kenal algoritma block chiper yang didalamnya terdapat AES (Anvanced Encyption Standard) merupakan bagian dari Modern Symmetric Key Cipher, algoritma ini menggunakan kunci yang sama pada saat proses enkripsi dan deskripsi sehingga data yang kita miliki akan sulit dimengerti maknanya. Teknik algoritma tersebut digunakan untuk mengkonversi data dalam bentuk kode-kode tertentu, untuk tujuan agar informasi yang tersimpan tidak bisa di baca siapa pun kecuali orang-orang yang berhak. Oleh karena itu, sistem keamanan data sangat di perlukan untuk menjaga kerahasian informasi agar tetap terjaga.
\end{abstract}

Kata kunci: Algoritma, Kriptografi, AES, Enkripsi, Deskripsi

\begin{abstract}
Data is a valueable for all computer users, cryptography is the one of method used to securing data. Cryptography is the study of mathematical techniques in securing an information or original message (Plainteks) into a hidden text (Chiperteks) and then converted into the original message again. Cryptography has three important elements, first is key generation, second is encryption and latetly is description. In cryptography known as cipher block algorithms in which AES (Advanced Encyption Standard) is part of Modern Symmetric Key Cipher, this algorithm uses the same key during the encryption and description process so that the data we have will be difficult to understand. The algorithm technique is used to convert data in the form of certain codes, so that the information stored cannot be read by anyone except those who are entitled. Therefore, the data security system is very necessary to maintain the confidentiality of information.
\end{abstract}

Keywords: Algoritma, Kriptografi, AES, Enkripsi, Deskripsi

http://dx.doi.org/10.15408/jti.v11i2.7811 


\section{PENDAHULUAN}

Seiring dengan kemajuan teknologi informasi maka sangat di perlukan sebuah keamanan data terhadap kerahasiaan informasi yang saling di pertukarkan melalui jaringan internet, apa lagi jika data tersebut dalam suatu jaringan komputer yang terhubung/terkoneksi dengan jaringan lain. Hal tersebut tentu saja menimbulkan resiko bila informasi yang sensitif dan berharga tersebut di akses oleh orang yang tidak bertangung jawab. Yang mana jika hal tersebut sampai terjadi, kemungkinan besar akan merugikan bahkan membahayakan orang yang akan mengirim pesan, maupun organisasinya. Informasi yang terkandung di dalamnya pun bisa saja berubah sehingga menyebabkan salah penafsiran oleh penerima pesan. Selain itu data yang dibajak kemungkinan rusak atau hilang yang menimbulkan kerugian material yang besar.

Pada penelitian sebelumnya telah dirancang aplikasi penyisipan teks pada gambar dengan algoritma blowfish dan least significant bit [7] namun agoritma tersebut sangat mudah di tebak oleh orang yang tidak bertanggung jawab. Oleh karena itu untuk menghindari agar hal tersebut tidak terjadi, penulis menggunakan algoritma kriptografi AES untuk proses enkripsi dan deskripsi data. Kriptografi telah menjadi suatu bagian yang tidak dapat di pisahkan dari sistem keamanan jaringan, salah satu metode enkripsi data adalah Advanced Encryption Standard (AES). .

\section{TINJAUAN PUSTAKA}

\subsection{Definisi Perancangan}

Pada saat hendak membuat sebuah sistem yang akan digunakan oleh pengguna (user), setiap pengembang aplikasi diharuskan membuat sebuah rancangan dari sistem yang ingin dibuat. Rancangan ini bertujuan untuk memberi gambaran umum dari sistem yang akan berjalan kepada setiap pengguna. Perancangan adalah sekumpulan aktivitas yang menggambarkan secara rinci bagaimana sistem akan berjalan. Hal itu bertujuan untuk menghasilkan produk perangkat lunak yang sesuai dengan kebutuhan pengguna (user).

\subsection{Pengamanan Data}

Secara umum data dikategorikan menjadi dua, yaitu data yang bersifat rahasia dan data yang tidak bersifat rahasia. Data yang tidak bersifat rahasia biasanya tidak akan terlalu diperhatikan. Yang sangat perlu diperhatikan adalah data yang bersifat rahasia, dimana setiap informasi yang ada didalamnya akan sangat berharga bagi pihak yang membutuhkan karena data tersebut dapat dengan mudah digandakan. Untuk mendapatkan informasi didalamnya, biasanya dilakukan berbagai cara yang tidak sah.

\subsection{Algoritma}

"Algoritma adalah urutan langkahlangkah logis penyelesaian masalah yang disusun secara sistematik dan logis". Kata logis merupakan kata kunci dalam algoritma. Langka-langka dalam algoritma harus logis dan harus dapat ditentukan bernilai salah atau benar [5].

\subsection{Definisi Kriptografi}

Kriptografi merupakan ilmu sekaligus seni untuk menjaga keamanan pesan (Cryptography is the art and science of keeping messages secure) selain itu ada pengertian tentang kriptografi yaitu kriptografi merupakan ilmu yang mempelajari teknikteknik matematika yang berhubungan dengan aspek keamanan informasi seperti kerahasiaan, integritas data, serta otentikasi. Kata "seni" di dalam definisi di atas maksudnya adalah mempunyai cara yang unik untuk merahasiakan pesan. Kata "graphy" di dalam "cryptography" itu sendiri sudah menyiratkan sebuah seni [5].

Untuk dapat menjalankan dengan baik pada proses kriptografi haruslah terdapat emapat elemen utama didalamnya, yang paling berkait satu sama lain. Yaitu :

1. Plain Text

Merupakan sebagai pesan awal atau pesan asli yang di kirim pada proses komunikasi. Plain Text inilah yang kemudian di enkripsi dan di deskripsi.

2. Cipher Text

Merupaka pesan yang tersembunyi, yaitu pesan asli (Pain Text) yang telah di enkripsi dapa proses kriptografi. Cipher Text ini dapat diubah kembali kebentuk aslinya (Pain Text) memanfaatkan Key yang telah di sediakan.

3. Cryptography Key

Merupakan kunci yang di gunakan untuk melakukan enkripsi dan deskripsi pada proses kriptografi. Tanpa adanya kunci (key) yang sama maka proses enkripsi dan deskripsi tidaka dapat dilakukan dengan baik. Kunci (key) merupakan informasi yang padat menjadi kendali terhadap proses terjadinya kriptografi. 
4. Encryption Decryption Algorithm

Komponen terakhir yang juga samapentingnya dalam proses kriptografi adalah algoritma yang di gunakan untuk enkripsi dan dekripsi.

Jenis serangan berdasarkan cara dan posisi seseorang untuk mendapatkan pesanpesan dalam jaringan, yaitu :

1. Sniffing

Sniffing berarti 'mengendus', dalam hal ini yang diendus merupakan pesan (baik yang belum ataupun yang sudah di enkripsi) dalam suatu saluran komunikasi. Hal ini umum terjadi pada saluran publik yang tidak aman yang mengakbatkan sang pengendus dapat merekam pembicaraan yang terjadi.

2. Replay Attack

Replay Attack adalah serangan jaringan dimana penyerang menyadap percakapan antara pengirim dan penerima, serta mengambil informasi autentik dengan berbagi kunci. Penyerang kemudian menghubungi penerima dengan kunci itu sebagai bukti identitas dan keaslian untuk menipu penerima.

Misalkan Yudhit mencuri informasi yang dikirimkan Bagas ke Salsa selanjutnya mengubah pesan tersebut sebelum dikirim kembali ke Salsa seolah pesan tersebut asli dari Bagas.

3. Spoofing

Spoofing adalah teknik untuk memperoleh akses yang tidak sah ke suatu komputer atau informasi dimana penyerang berhubungan dengan pengguna dengan berpura-pura sebagai host yang dapat dipercaya. Spoofing biasanya dilakukan oleh seorang hakcer/craker.

Sebagai contoh, Seorang penyerang (misalnya Yudhit) bisa menyamar menjadi Bagas. Semua orang dibuat percaya bahwa Yudhit adalah Bagas. Penyerang berusaha meyakinkan kepada pihak-pihak lain bahwa tidak ada yang salah dengan komunikasi yang dilakukan. Padahal komunikasi itu dilakukan dengan penipu/penyerang.

4. Man-in-the-middle

Jika spoofing kadang hanya menipu satu pihak, dalam skenario ini saat Bagas hendak berkomunikasi dengan Salsa, Yudhit dimata Bagas seolah-olah menjadi Salsa. Ydhit juga dapat menipu Salsa sehingga ia seolah-olah adalah Bagas. Yudhit dapat berkuasa penuh atas jalur komunikasi dan bisa membuat berita fitnah.

\subsection{Definisi Advanced Encryption Standard (AES)}

Advanced Encryption Standard (AES) merupakan algoritma cryptographic yang dapat digunkan untuk mengamakan data. Algoritma AES adalah blok chipertext simetrik yang dapat mengenkripsi (encipher) dan dekripsi (decipher) informasi. Enkripsi merubah data yang tidak dapat lagi dibaca disebut ciphertext; sebaliknya dekripsi adalah merubah ciphertext data menjadi bentuk semula yang kita kenal sebagai plaintext. Algoritma AES menggunakan kunci kriptografi 128, 192, dan 256 bits untuk mengenkrip dan dekripsi data.

Secara umum metode yang digunakan dalam pemrosesan terbagi dua, yaitu

1. Enkripsi

Enkripsi adalah proses penyandian plaintext menjadi ciphertext, atau pengubahan data menjadi bentuk rahasia.

Proses enkripsi algoritma AES terdiri dari 4 jenis transformasi bytes, yaitu SubBytes, ShiftRows, Mixcolumns, dan AddRoundKey. Pada awal proses enkripsi, input yang telah dicopykan ke dalam state akan mengalami transformasi byte AddRoundKey. Setelah itu, state akan mengalami transformasi SubBytes, ShiftRows, MixColumns, dan AddRoundKey secara berulang-ulang sebanyak Nr. Proses ini dalam algoritma AES disebut sebagai round function. Round yang terakhir agak berbeda dengan round-round sebelumnya dimana pada round terakhir, state tidak mengalami transformasi MixColumns.

2. Dekripsi

Dekripsi adalah proses memperoleh kembali plaintext menjadi ciphertext, atau proses pengubahan kembali data yang berbentuk rahasia menjadi semula. Transformasi byte yang digunakan pada invers cipher adalah InvShiftRows, InvSubBytes, InvMixColumns, dan AddRoundKey. 


\section{METODOLOGI}

Studi Pustaka (literature study) dilaksanakan dengan cara mengumpulkan dan mempelajari segala macam informasi yang berhubungan dengan kriptografi, algoritma $A E S$ dan segala hal yang berhubungan dengan model pemrogramannya, bisa melalui buku dan internet.

Metode Pengembangan Sistem

1. Analisa Kebutuhan

Perkembangan teknologi informasi dan komunikasi sangat cepat dan pesat, hal ini yang menyebabkan munculnya kemajuan teknologi informasi. Maka sangat di perlukan sebuah keamanan data terhadap kerahasiaan informasi yang saling di pertukarkan melalui jaringan internet. Pembuatan software aplikasi sistem keamanan data menggunakan Microsoft Visual Studio 2010. Microsoft Visual Studio 2010 mengatasi semua masalah pengembangan apliakasi berbasis Windows dan memiliki fasilitas penanganan Bug yang hebat dan Real Time Backroud Compiler. Hal ini akan memberi kontribusi yang kuat dalam sistem enkripsi dan deskripsi. Dan harus menganalisa terlebih dahulu proses enkripsi dan dekripsi pada algoritma AES Rijndael.

2. Desain Sistem

Pada tahap ini dilaksanakan perancangan Aplikasi Sistem yang akan dibuat berdasarkan hasil Studi Pustaka (study literature) yang ada. Perancangan Aplikasi sistem ini meliputi desain menu utama yang terdiri dari enkripsi dekripsi file dan teks serta pemrograman. Perencanaan penggunaan bahasa pemrograman Microsoft Visual Studio 2010.

3. Implementasi

Dalam tahap ini, dilakukan implementasi berdasarkan studi pustaka dan rancangan yang telah dibuat pada tahap sebelumnya, dalam bentuk program.

4. Uji Coba dan Evaluasi

Merupakan kegiatan mengevaluasi dan memperhalus analisis kebutuhan calon pengguna. Program yang sudah diuji coba program untuk mencari masalah yang mungkin timbul dan disempurnakan kemudian dievaluasi kebenaran dan kemampuannya terhadap sistem serta mengevaluasi jalannya program.
5. Analisa Hasil Uji Coba

Pada tahap ini dihasilkan uji coba dan beberapa revisi, jika terjadi kekurangan dan kesalahan terhadap perangkat lunak yang telah selesai dibuat dan diharapkan sistem aplikasi tersebut mengalami segala macam uji coba sehingga menghasilkan output yang diharapkan.

\section{ANALISA DAN PEMBAHASAN}

\subsection{Analisa Kebutuhan Software}

Perkembangan teknologi informasi dan komunikasi sangat cepat dan pesat, hal ini yang menyebabkan munculnya kemajuan teknologi informasi. Maka sangat di perlukan sebuah keamanan data terhadap kerahasiaan informasi yang saling di pertukarkan melalui jaringan internet.

\subsection{Identifikasi Permasalahan}

Seiring dengan kemajuan teknologi informasi yang semakin pesat maka sangat di perlukan sebuah keamanan data terhadap kerahasiaan informasi. Sangat banyak informasi yang sensitif dan berharga tersebut di akses oleh orang yang tidak bertangung jawab, kemungkinan besar akan merugikan bahkan membahayakan orang yang akan mengirim pesan, maupun penerimanya. Informasi yang terkandung di dalamnya pun bisa saja berubah sehingga menyebabkan salah penafsiran oleh penerima pesan. Selain itu data yang dibajak kemungkinan rusak atau hilang yang menimbulkan kerugian material yang besar. Oleh karena itu untuk menghindari agar hal tersebut tidak terjadi, penulis menggunakan algoritma kriptografi AES (Advanced Encryption Standard) untuk proses enkripsi dan deskripsi data.

\subsection{Analisa Kebutuhan}

Dalam kriptografi dikenal algoritma block chiper yang di dalamnya terdapat AES (Anvanced Encyption Standard) merupakan bagian dari Modern Symmetric Key Cipher, algoritma ini menggunakan kunci yang sama pada saat proses enkripsi dan deskripsi sehingga data yang kita miliki akan sulit dimengerti maknanya.

Teknik algoritma tersebut digunakan untuk mengkonversi data dalam bentuk kodekode tertentu, untuk tujuan agar informasi yang tersimpan tidak bisa di baca siapa pun kecuali orang-orang yang berhak. Oleh karena itu, sistem keamanan data sangat di perlukan 
untuk menjaga kerahasian informasi agar tetap terjaga.

Pembuatan software aplikasi sistem keamanan data menggunakan Microsoft Visual Studio 2010. Microsoft Visual Studio 2010 mengatasi semua masalah pengembangan apliakasi berbasis Windows dan memiliki fasilitas penanganan Bug yang hebat dan Real Time Backroud Compiler. Hal ini akan memberi kontribusi yang kuat dalam sistem enkripsi dan deskripsi.

\subsection{Desain Algoritma Pada Kasus \\ 4.4.1 Proses Enkripsi}

Proses enkripsi algoritma AES terdiri dari 4 jenis transformasi bytes, yaitu SubBytes, ShiftRows, Mixcolumns, dan AddRoundKey. Pada awal proses enkripsi, input yang telah dicopykan ke dalam state akan mengalami transformasi byte AddRoundKey. Setelah itu, state akan mengalami transformasi SubBytes, ShiftRows, MixColumns, dan AddRoundKey secara berulang-ulang sebanyak Nr. Proses ini dalam algoritma AES disebut sebagai round function. Round yang terakhir agak berbeda dengan round-round sebelumnya dimana pada round terakhir, state tidak mengalami transformasi MixColumns. Ilustrasi proses enkripsi AES dapat digambarkan seperti pada Gambar di bawah ini :

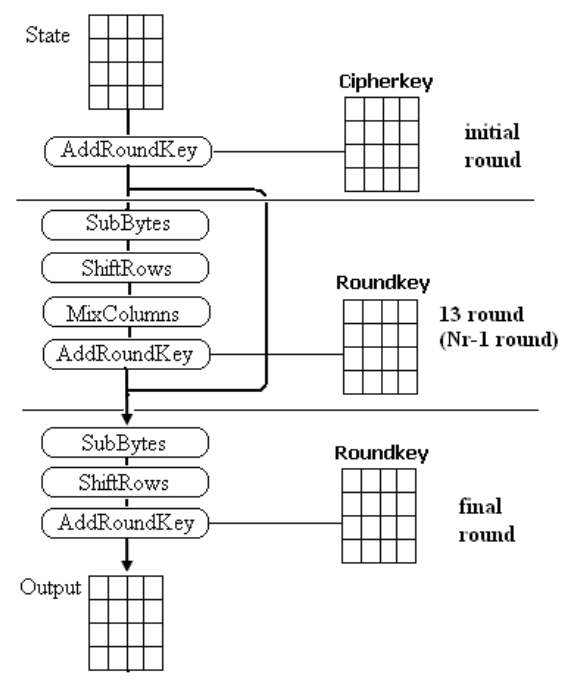

Gambar 1. Diagram enkripsi AES [5]

Garis besar algoritma AES Rijndael yang beroprasi pada blok 128-bit dengan kunci 128bit (diluar proses pembangkitan roundkey) adalah sebagai berikut :

1. AddRoundKey, melakukan XOR antara awal (plantext) dengan cipher key.
2. Putaran sebanyak Nr-1 kali. Proses yang dilakukan pada setiap putaran adalah :

a. SubBytes adalah subsitusi byte menggunakan tabel subsitusi ( $S$-Box).

b. ShiftRows adalah pergeseran barisbaris array state secara wrapping.

c. MixColumns adalah mengacak data di masing-masing kolom array state.

d. AddRoundKey adalah melakukan XOR antara state sekarang round key.

3. Final round, proses untuk putaran terakhir:
a. SubBytes
b. ShiftRows
c. AddRoundKey

Langkah kerja enkripsi adalah sebagai berikut:

a. Transformasi SubBytes

SubBytes merupakan transformasi byte dimana setiap elemen pada state akan dipetakan dengan menggunakan sebuah tabel substitusi ( S-Box ). Tabel substitusi S-Box akan dipaparkan dalam Tabel 1.

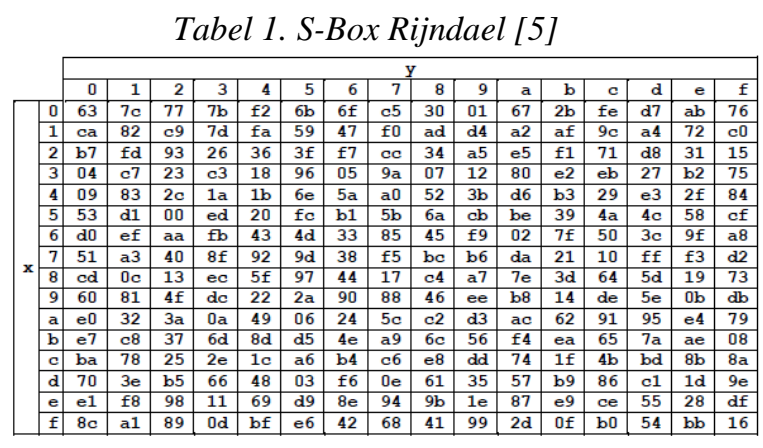

Untuk setiap byte pada array state, misalkan $S[r, c]=x y$, yang dalam hal ini $x y$ adalah digit heksadesimal dari nilai $S[r, c]$, maka nilai substitusinya, dinyatakan dengan $S^{\prime}[r, c]$, adalah elemen di dalam tabel subtitusi yang merupakan perpotongan baris $x$ dengan kolom $y$. Gambar 2 mengilustrasikan pengaruh pemetaan byte pada setiap byte dalam state.

\begin{tabular}{|c|c|c|c|c|c|c|c|c|}
\hline $\mathbf{S}_{0,0}$ & $\mathbf{S}_{0,1}$ & $\mathrm{~S}_{0,2}$ & $\mathbf{S}_{0,3}$ & S-Box & $\mathbf{S}^{\prime} 0,0$ & $\mathbf{S}_{0,1}^{\prime}$ & $\mathbf{S}_{0,2}^{\prime}$ & $\mathbf{S}_{0,3}^{\prime}$ \\
\hline $\mathbf{S}_{1,0}$ & $\mathrm{SrO}$ & & $\mathrm{S}_{1,3}$ & & $S_{1,0}^{\prime}$ & 54 & $8^{2}$ & $\mathbf{S}_{1,3}^{\prime}$ \\
\hline $\mathbf{S}_{2,0}$ & $\Delta<, 1$ & $\overline{\mathbf{S}_{22,2}}$ & $\mathbf{S}_{2,3}$ & & $\mathbf{S}_{2,0}^{\prime}$ & $S_{2, i}^{\prime}$ & $\mathbf{D}<, \overline{2}$ & $\mathbf{S}_{2,3}^{\prime 2}$ \\
\hline $\mathbf{S}_{3,0}$ & $\mathbf{S}_{3,1}$ & $\mathbf{S}_{3,2}$ & $\mathbf{S}_{3,3}$ & & $\mathbf{S}_{3,0}^{\prime}$ & $\mathbf{S}_{3,1}^{\prime}$ & $\mathbf{S}_{3,2}^{\prime}$ & $\mathbf{S}_{3,3}^{\prime}$ \\
\hline
\end{tabular}

Gambar 2. Pengaruh pemetaan pada setiapbByte dalam state [3]

\section{b. Shiftrows}

Transformasi Shiftrows pada dasarnya adalah proses pergeseran bit dimana bit paling kiri akan dipindahkan menjadi bit paling kanan 
(rotasi bit). Proses pergeseran Shiftrow ditunjukkan dalam Gambar III.3 berikut:

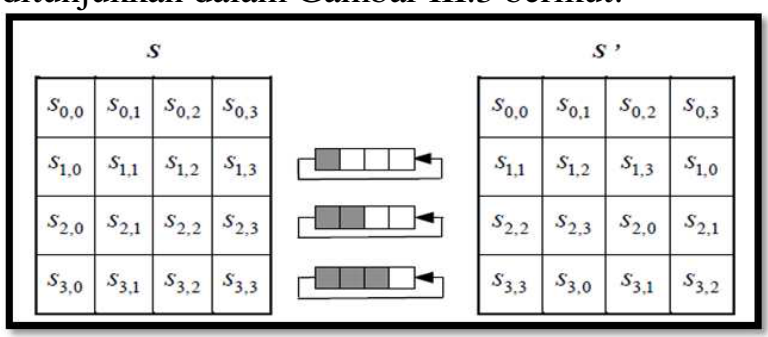

Gambar 3. Proses shifrows [5]

\section{c. MixColumns}

MixColumns mengoperasikan setiap elemen yang berada dalam satu kolom pada state. Secara lebih jelas, transformasi mixcolumns dapat dilihat pada perkalian matriks berikut ini:

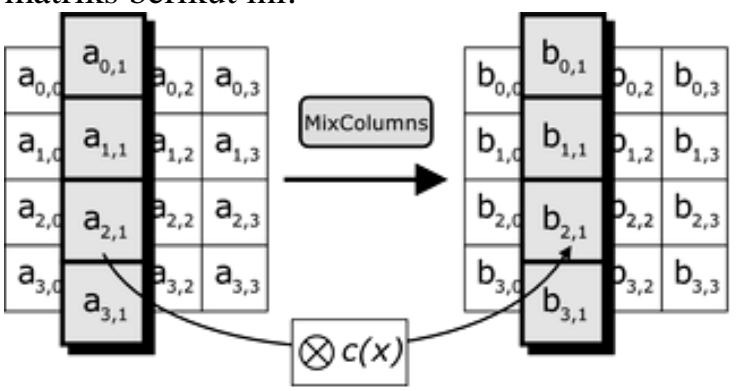

Gambar 4. Proses mixcolumns [5]

d. AddRoundKey

AddRoundKey: melakukan XOR antara state sekarang dengan round key.

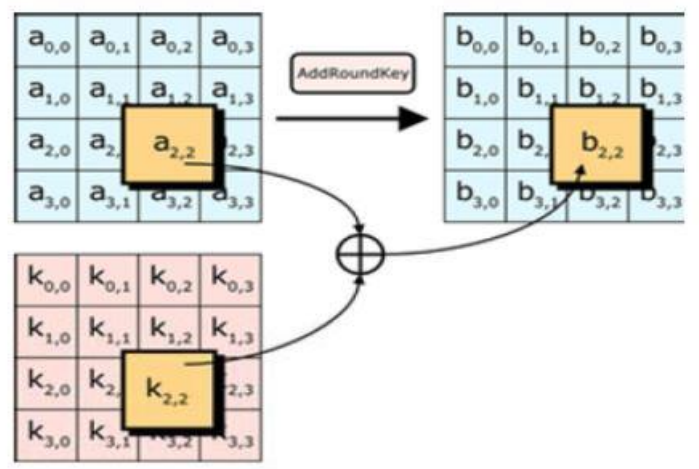

Gambar 5. Proses addroundKey [5]

\subsubsection{Proses Dekripsi}

Transformasi cipher dapat dibalikkan dan diimplementasikan dalam arah yang berlawanan untuk menghasilkan inverse cipher yang mudah dipahami untuk algoritma AES. Transformasi byte yang digunakan pada invers cipher adalah InvShiftRows, InvSubBytes, InvMixColumns, dan AddRoundKey. Algoritma dekripsi dapat dilihat pada skema berikut ini :

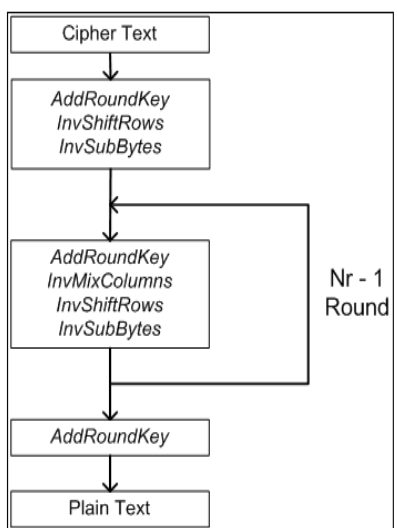

Gambar 6. Proses dekripsi [5]

\section{a. InvShiftRows}

InvShiftRows adalah transformasi byte yang berkebalikan dengan transformasi ShiftRows. Pada transformasi InvShiftRows, dilakukan pergeseran bit ke kanan sedangkan pada ShiftRows dilakukan pergeseran bit ke kiri. Ilustrasi transformasi InvShiftRows terdapat pada Gambar 7:

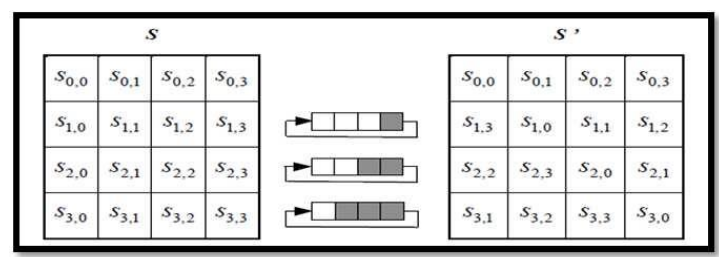

Gambar 7. Proses invshiftrows [5]

\section{b. InvSubBytes}

InvSubBytes juga merupakan transformasi bytes yang berkebalikan dengan transformasi SubBytes. Pada InvSubBytes, tiap elemen pada state dipetakan dengan menggunakan tabel Inverse S-Box.

\begin{tabular}{|c|c|c|c|c|c|c|c|c|c|c|c|c|c|c|c|c|c|}
\hline \multirow{2}{*}{ Hex } & & \multicolumn{16}{|c|}{$\mathbf{Y}$} \\
\hline & & 0 & 1 & 2 & 3 & 4 & 5 & 6 & 7 & 8 & 9 & $\mathrm{a}$ & $\mathrm{b}$ & $c$ & $\mathrm{~d}$ & e & $\mathrm{f}$ \\
\hline \multirow{16}{*}{$\mathbf{x}$} & & 52 & 09 & 6a & $\mathrm{d} 5$ & 30 & 36 & a5 & 38 & bf & 40 & a3 & $9 \mathrm{e}$ & 81 & $\mathrm{f3}$ & $\mathrm{d} 77$ & $\mathrm{fb}$ \\
\hline & & $7 \mathrm{c}$ & E3 & 39 & 82 & $9 \mathrm{~b}$ & $2 \mathrm{f}$ & $\mathrm{ff}$ & 87 & 34 & $8 \mathrm{e}$ & 43 & 44 & c4 & de & e9 & $\mathrm{cb}$ \\
\hline & 2 & 54 & $7 b$ & 94 & 32 & a6 & c2 & 23 & $3 \mathrm{~d}$ & ee & $4 c$ & 95 & $0 \mathrm{~b}$ & 42 & fa & $\mathrm{c} 3$ & $4 \mathrm{e}$ \\
\hline & & 08 & $2 e$ & a1 & 66 & 28 & d9 & 24 & b2 & 76 & $5 b$ & a2 & 49 & $6 \mathrm{~d}$ & $8 b$ & $\mathrm{~d} 1 \mathrm{l}$ & 25 \\
\hline & t & 72 & f8 & f6 & 64 & 86 & 68 & 98 & 16 & $\mathrm{~d} 4$ & a4 & $5 c$ & $\mathrm{cc}$ & $5 \mathrm{~d}$ & 65 & b6 & 92 \\
\hline & 5 & $6 \mathrm{c}$ & 70 & 48 & 50 & $\mathrm{fd}$ & ed & b9 & $\mathrm{da}$ & $5 \mathrm{e}$ & 15 & 46 & 57 & a7 & $8 \mathrm{~d}$ & $9 \mathrm{~d}$ & 84 \\
\hline & 5 & 90 & $\mathrm{~d} 8$ & $\mathrm{ab}$ & 00 & $8 \mathrm{c}$ & $\mathrm{bc}$ & $\mathrm{d} 3$ & $0 \mathrm{a}$ & 17 & e4 & 58 & 05 & b8 & b3 & 45 & 06 \\
\hline & & d0 & $2 c$ & le & $8 \mathrm{f}$ & $\mathrm{ca}$ & $3 \mathrm{f}$ & of & 02 & c1 & af & bd & 03 & 01 & 13 & $8 a$ & $6 \mathrm{~b}$ \\
\hline & 8 & $3 a$ & 91 & 11 & 41 & $4 \mathrm{f}$ & 67 & $\mathrm{dc}$ & ea & 97 & f2 & cf & $\mathrm{ce}$ & fo & b4 & e6 6 & 73 \\
\hline & ) & 96 & ac & 74 & 22 & e7 & ad & 35 & 85 & e2 & f9 & 37 & e8 & $1 \mathrm{c}$ & 75 & $\mathrm{df}$ & $6 \mathrm{e}$ \\
\hline & & 47 & f1 & 1a & 71 & $1 \mathrm{~d}$ & 29 & c5 & 89 & $6 \mathrm{f}$ & b7 & 62 & $0 \mathrm{e}$ & aа & 18 & be & $1 \mathrm{~b}$ \\
\hline & , & $\mathrm{fc}$ & 56 & $3 \mathrm{e}$ & $4 \mathrm{~b}$ & c6 & $\mathrm{d} 2$ & 79 & 20 & $9 a$ & $\mathrm{db}$ & $\mathrm{c} 0$ & fe & 78 & $\mathrm{~cd}$ & $5 a$ & $\mathrm{f} 4$ \\
\hline & & 1f & $\mathrm{dd}$ & a8 & 33 & 88 & 07 & c7 & 31 & b1 & 12 & 10 & 59 & 27 & 80 & $\mathrm{ec}$ & $5 f$ \\
\hline & & 60 & 51 & $7 \mathrm{f}$ & a9 & 19 & b5 & $4 a$ & $\mathrm{Od}$ & $2 \mathrm{~d}$ & e5 & $7 a$ & $9 \mathrm{f}$ & 93 & c9 & $9 \mathrm{c}$ & ef \\
\hline & & a0 & $\mathrm{e} 0$ & $3 b$ & $4 \mathrm{~d}$ & ae & $2 a$ & f5 & b0 & $\mathrm{c} 8$ & eb & $\mathrm{bb}$ & $3 c$ & 83 & 53 & 99 & 61 \\
\hline & & 17 & $2 \mathrm{~b}$ & 04 & $7 \mathrm{e}$ & $\mathrm{ba}$ & 77 & d6 & 26 & e1 & 69 & 14 & 63 & 55 & 21 & $0 \mathrm{c}$ & $7 \mathrm{~d}$ \\
\hline
\end{tabular}

Gambar 8. Proses invsubbytes [5] 


\section{c. InvMixColumns}

Setiap kolom dalam state dikalikan dengan matrik perkalian dalam AES. Perkalian dalam matrik dapat dituliskan :

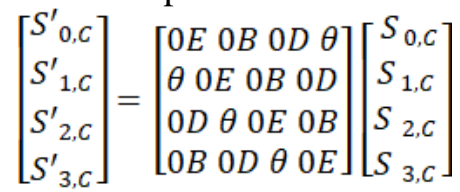

Hasil dari perkalian matriks adalah

$S^{\prime}{ }_{0 . C}=\left(\{0 E\} \cdot S_{0, C}\right) \oplus\left(\{0 B\} \cdot S_{1 . C}\right) \oplus\left(\{0 D\} \bullet S_{2, C}\right) \oplus\left(\{\theta\} \bullet S_{3 . C}\right)$

$S_{1, C}^{\prime}=\left(\{\theta\} \cdot S_{0, C}\right) \oplus\left(\{0 E\} \cdot S_{1, C}\right) \oplus\left(\{0 B\} \bullet S_{2, C}\right) \oplus\left(\{0 D\} \bullet S_{3, C}\right)$

$S_{2, C}^{\prime}=\left(\{0 D\} \cdot S_{0, C}\right) \oplus\left(\{\theta\} \cdot S_{1, C}\right) \oplus\left(\{0 E\} \cdot S_{2, C}\right) \oplus\left(\{0 B\} \cdot S_{3, C}\right)$

$S_{3 . C}^{\prime}=\left(\{0 B\} \cdot S_{0, C}\right) \oplus\left(\{0 D\} \cdot S_{1 . C}\right) \oplus\left(\{\theta\} \cdot S_{2, C}\right) \oplus\left(\{0 E\} \cdot S_{3 . C}\right)$

d. Inverse AddRounKey

Transormasi Inverse AddRounKey tidak berbeda dengan transformasi AddRoundkey karna dalam transformasi ini hanya dilakukan operasi penambahan sederhana dengan operasi bitwise XOR.

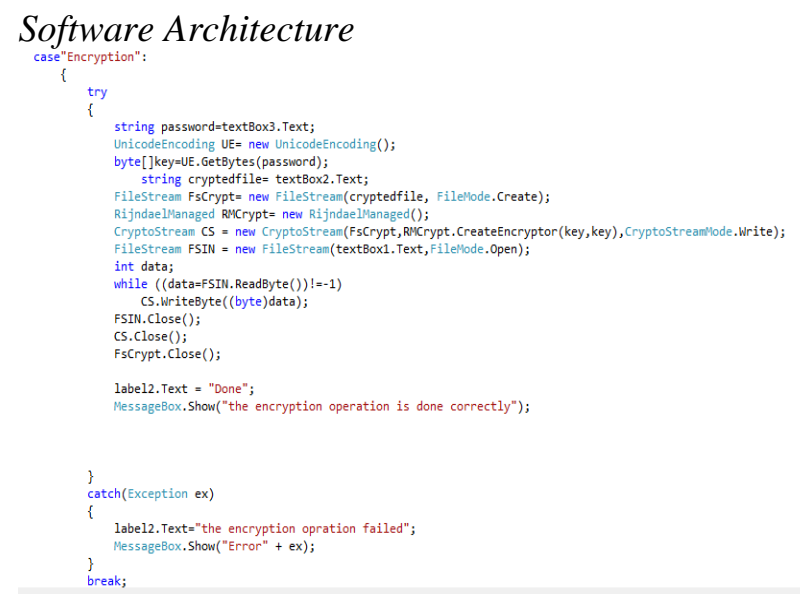

Gambar 9. Proses Enkripsi

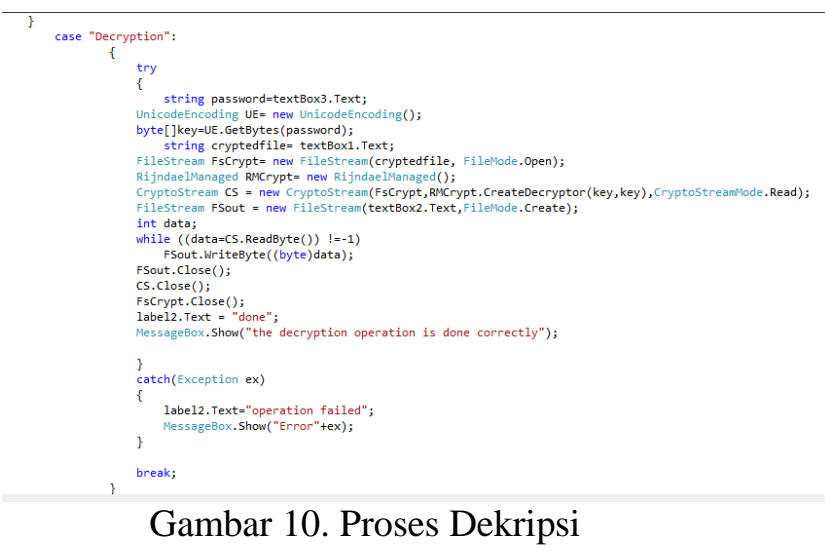

\subsubsection{User Interface}

Pada Perancangan aplikasi ini terdapat dua keguanan, yaitu untuk enkripsi dan dekripsi file serta untuk enkripsi dan dekripsi text. Tampialan awal aplikasi yang dibuat seperti ini:

1. Perancangan Enkripsi dan Dekripsi File

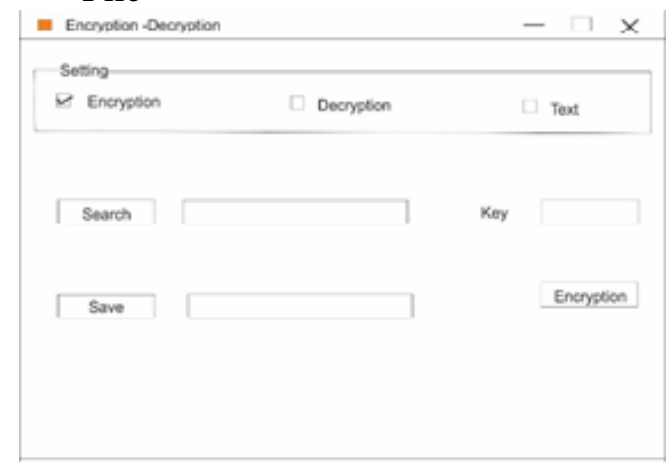

Gambar 11. Perancangan enkripsi dan dekripsi file

Untuk mengenkripsi atau mengdekripsi data file, pilih Encryption atau Decryption dalam kotak Setting. Kemudian cari (Search) file data yang dituju dan simpan (Save) di folder tertentu, masukan kunci (Key) 8 karakter dan jalankan program. Hasil akan langsung tersimpan di folder yang telah dipilih sebelumnya.

2. Perancangan Enkripsi dan Dekripsi Data

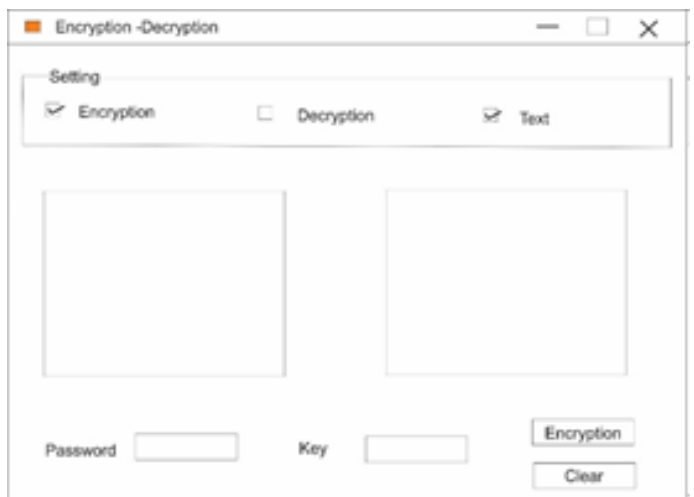

Gambar 12. Perancangan enkripsi dekripsi teks

Pengubahan text menjadi kode-kode atau sebaliknya. Sebelumnya pilih Text pada kotak Setting. Tuliskan text di kotak kiri, masukan password dan key 8 karakter kemudian jalankan program enkripsi. Dan hasil enkripsi akan muncul dikotak kanan. Pengubahan dari dekripsi ke enkripsi tuliskan kode-kode yang berbentuk kalimat yang telah dienkripsi ke dalam kotak kanan, pilih setting dekripsi masukan password dan key 8 karakter, dan hasilnya dekripsi akan muncul di kotak kiri. 


\subsubsection{Testing}

Perancangan Struktur Program

Adapun struktur program dalam aplikasi keaman data enkripsi dan dekripsi adalah sebagai berikut:

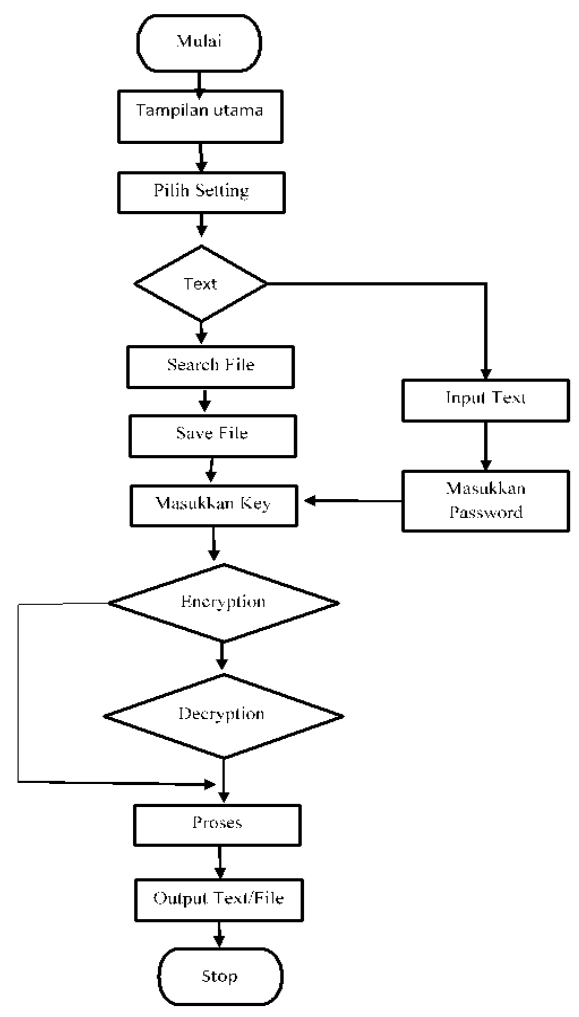

Gambar 13. Struktur program menu utama

\subsubsection{Perancangan Aplikasi Enkripsi Deskripsi}

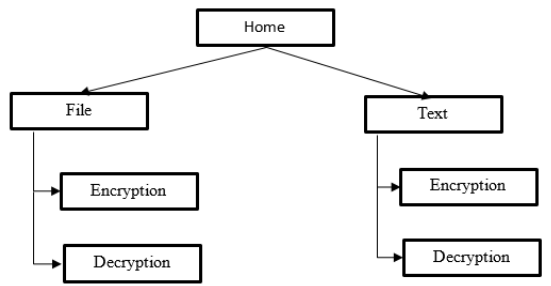

Gambar 14. Perancangan aplikasi enkripsi dekripsi

\subsubsection{Implementasi}

Implementasi algorotma AES

(Advanced Encryption Standard) Rijdael dibuat Menggunakan Microsoft Visual Studio 2010. Aplikasi yang terdiri dari enkripsi dekripsi text dan enkripsi dekripsi file.

\subsubsection{Implementasi Encryption File}

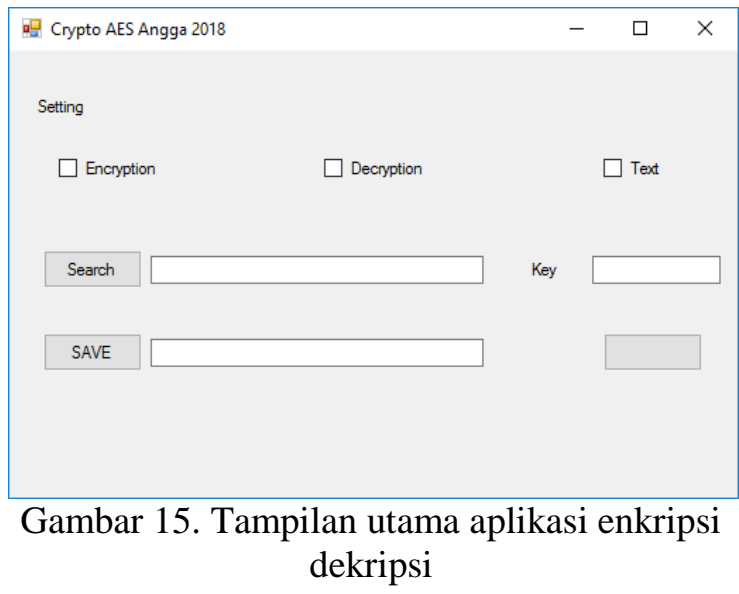

Pada tampilan utama aplikasi terdapat setting yang terdiri dari encryption, decryption, dan text. Serta difungsikan langsung untuk enkripsi atau dekripsi file.

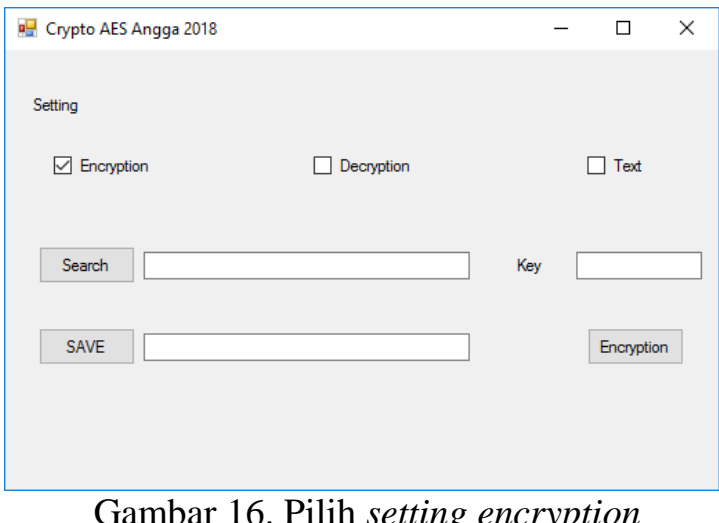

(2inushiftrows - Notepad

$-\square \times$

File Edit Format View Help

InvShiftRows adalah transformasi byte yang

berkebalikan dengan transformasi ShiftRows.

Pada transformasi InvShiftRows,

dilakukan pergeseran bit ke kanan sedangkan pada

ShiftRows dilakukan pergeseran bit ke kiri.

Gambar 17. File yang akan dienkripsi

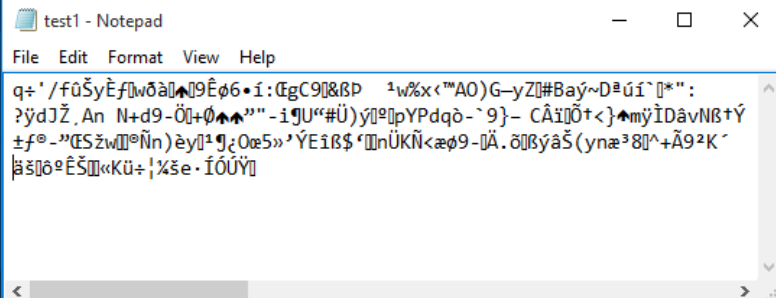

Gambar 18. Hasil enkripsi

Pada enkripsi dekripsi file, file yang akan dienkripsi ialah file-file yang terdapat 
dalam sistem komputer seperti file Microsoft Office, file MP3, file PDF, dan file gambar. File yang telah dienkripsi akan berekstensi aes dan untuk melihat hasil dari enkripsi file tersebut dapat dilihat menggunakan notepad.

\subsubsection{Implementasi Text}

\section{Encryption Text}

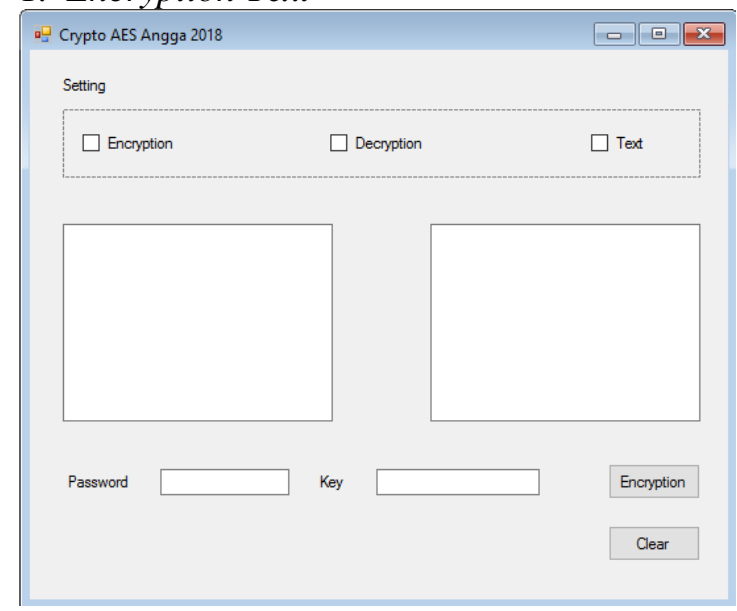

Gambar 19. Mengenkripsi text

Pada setting terdapat pilihan text untuk mengenkripsi dekripsi text, dan tampilan aplikasi kemudian berubah seperti pada Gambar 20.

Untuk enkripsi teks, tuliskan teks pada kolom kiri dan hasilnya akan muncul dikolom kanan. Dan jika mendekripsi teks, menginput text enkripsi pada kolom kanan kemudian hasil teks dekripsi akan muncul di kolom kiri.

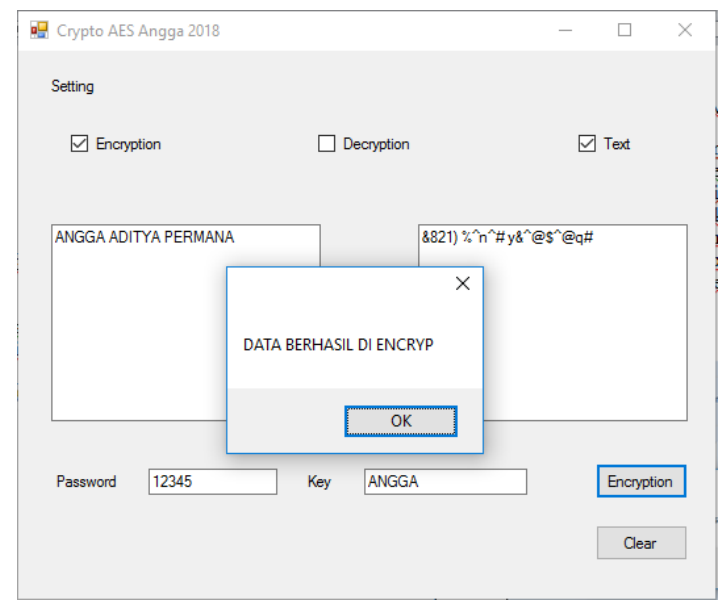

Gambar 20. Enkripsi text berhasil

\subsubsection{Decryption Text}

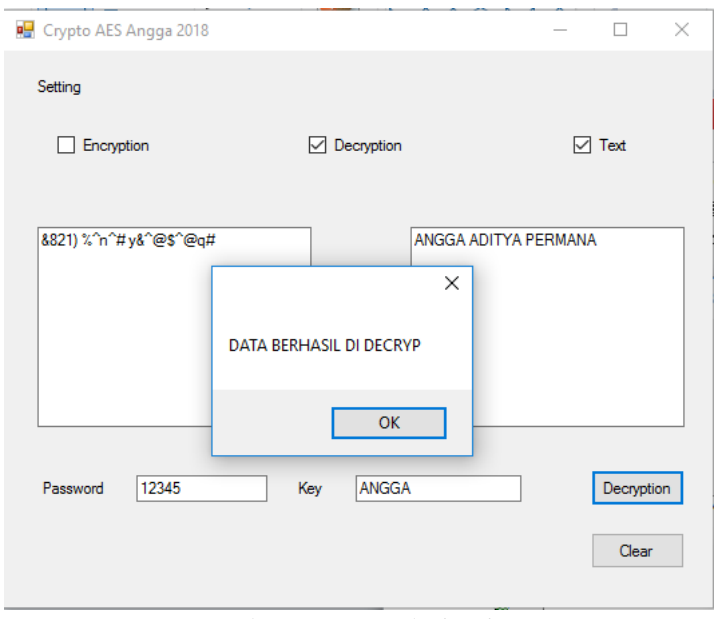

Gambar 21. Dekripsi text

Pada enkripsi file dan teks jika terjadi perubahan kunci, maka hasilnya tidak akan terbaca dan dingggap file tersebut rusak. Jika terjadi perbedaan, maka disimpulkan ada modifikasi terhadap isi pesan. Aplikasi ini didasarkan pada kenyataan bahwa perubahan kunci akanmenyebabkan perubahan data pada saat akan dikembalikan pada bentuk semula atau didekripsi dan hasilnya akan berbeda dengan aslinya (plainteks). Dengan kata lain, Rijndael sangat peka terhadap perubahan sekecil apa pun pada data masukan.

\section{PENUTUP}

Pembuatan aplikasi sistem pengamanan data enkripsi dekripsi file dan teks menggunakan Microsoft Visual Studio 2010 mendukung perkembangan zaman yang semakin canggih. Pemilihan algoritma algoritma AES: Rijndael, karena algoritma ini merupakan algoritma yang cukup sulit dipecahkan saat ini, sebab belum ada serangan atau pemecahan yang belum mampu secara analisis matematika dengan efektif dan efesien dengan alasan pola yang dibentuk cukup acak. AES: Rijndael memiliki keunggulan karena memiliki daya memori dan kecepatan komputasi dalam pengoprasian. Pengoprasian yang tidak memakan memori yang telalu besar ini banyak diminati pasar karena kebutuhan efesiensi waktu yang relatif cepat.

Diharapkan kepada pembaca yang melakukan proses enkripsi dan dekripsi file ataupun teks untuk menggunkan kunci yang lebih variatif atara huruf dan angka ataupun 
karakter yang akan lebih menyulitkan pemecahan cipherteks oleh kriptanalis.

\section{DAFTAR PUSTAKA}

[1] Agus Eka Pratama, I Putu. 2014. Handbook Jaringan Komputer. Bandung: Informatika.

[2] Anhar. 2010. Cara Mudah Mengamankan Data Komputer dan Laptop. Jakarta: Media Kita.

[3] Ncbnzx Fachrurozi, Muhammad Farid. 2006. Enkripsi Pesan Rahasia Menggunakan Algoritma (Advandes Encryption Standard) AES: Rijndael. Jakarta: Universitas Islam Negri Syarif Hidayatullah Jakarta.

[4] Ibrahim, Rohmat Nur. 2012. Kriptografi Algoritma DES, AES/Rijndael, Blowfish Untuk Keamanan Citra DigitalDengan Menggunakan Metode Discrete Wavelete Transformasion (DWT). ISSN: 2442-4943. Bandung: Jurnal Computech and Bisnis, Vol. 6, No.2, Desember 2012, 82-95.

[5] Munir, Rinaldi. 2006. Kriptografi. Bandung: Informatika Bandung.

[6] Permana AA, 2016. Rancangan Sistem Informasi Simpan Pinjam Pada Koperasi Guru Dan Pegawai SMP Negeri 45 Jakarta. ISSN: 2088-0154. Vol 8, No 1 - 2016

[7] Permana AA, 2017. Aplikasi penyisipan teks pada gambar dengan algoritma blowfish dan least significant bit. ISSN: 2549-0710. Tangerang: Jurnal Informatika, Vol 1, No 1 Januari 2017, 11-17.
[8] Primartha, Rifkie. 2013. Penerapan Enkripsi dan Dekripsi File Menggunakan Algoritma Advens Encryption Standard (AES). ISSN: 2301-8488. Palembang: Journal of Research in Computer Science and Applications - Vol. 2, No. 1, Januari 2013: 13-18.

[9] Rahmayunita, Isnawaty, Sutardi. 2015. Penyadapan SMS dan GPS Berbasis Android Menggunakan Algoritma Advanced Encryption Standard (AES). ISSN: 2460-1446. Kendari. SemanTIK, Vol. 1, No.2, Juli-Desember 2015, pp. 11-22.

[10] Riadi, Muchlisin. 2014. Pengertian, Sejarah dan Jenis Kriptografi. Diambil dari:

http://www.kajianpustaka.com/2014/01/ pengertian-sejarah-dan-jeniskriptografi.html? $\mathrm{m}=1$.

[11] Satria, Eko. 2009. Studi Algoritma Rijndael dalam Sistem Keamanan Data. Sumatra Utara: USU Repository.

[12] Setyaningsih, Emy. 2015. Kriptografi dan Implementasinya Menggunakan MATLAB. Yogyakarta: Andi

[13] Sianturi, Fricles Ariwisanto. 2013. Perancangan Aplikasi Pengamanan Data Dengan Kriptografi Advances Encryption Standard (AES). ISSN: 2301-9425. Medan: Pelita Informatika Budi Darma, Vol. 4, No. 1, Agustus 2013: 42-46.

[14] Sutejo, Budi dan Michael. 2004. Algoritma dan Teknik Pemprograman. Yogyakarta:

Andi 